\title{
The US Needs Tort Replacement, Not Just "Reform"
}

\section{Waldman JD}

Health Sciences Center and the RO Anderson School of Management, University of New Mexico

*Corresponding author: Deane Waldman J, Health Sciences Center and the RO Anderson School of Management, University of New Mexico, Albuquerque, NM 87131, USA, Tel: 505-272-8780; E-mail: dw@deanewaldman.com

Received: Feb 6, 2014; Accepted: Mar 24, 2014; Published: Mar 28, 2014

Copyright: (c) 2014 Waldman JD. This is an open-access article distributed under the terms of the Creative Commons Attribution License, which permits unrestricted use, distribution, and reproduction in any medium, provided the original author and source are credited.

\begin{abstract}
The US medical malpractice system is analyzed using a systems thinking approach: comparing intended purposes - by the designers - with the expected outcomes - by the Public. Both intended as well as unintended consequences of the medical malpractice system are described. Differences between actual outcomes and expectations explain why there is much dissatisfaction.

The tort model is shown to be inappropriate for adjudication of medical injuries. Because the system is conceptually flawed, no amount of 'reform' can produce the intended outcomes nor can any modification of the existing system satisfy the Public. An alternative system is proposed based on No-Fault principles.
\end{abstract}

Keywords Clinical negligence; Medical malpractice; Medical errors; Medical quality; Medical costs; Learning; Justice

\section{Introduction}

In the U.S.A., the phrase "tort reform" refers to revision of the system intended to adjudicate medical injuries. That system, called medical malpractice (abbreviated as Med-Mal) in the USA and called clinical negligence in Great Britain, is a "malprocess," [1] a process or system that consistently fails to achieve its desired effects. Med-Mal fails to help injured patients. Med-Mal is dollar inefficient and overly expensive. Med-Mal actively constrains improvement. This malprocess is due to fundamental design or conceptual flaw. As such, it must be replaced. It cannot simply be revised, adjusted or reformed.

\section{Purpose of the Medical Malpractice System}

A successful fix of any malfunctioning system starts by comparing what the system is expected to do to what it actually does. Without this step, as systems thinking teaches, the result is usually a fix-that-failsor-backfires. The public-as patients-expects Med-Mal to help them when they are medically injured, to weed out dangerous providers, and to improve the quality of medical care they receive. Med-Mal was never designed to accomplish those goals.

Modeled on the tort concepts, Med-Mal was created with two and only two purposes: 1) Identify (and presumably punish) the perpetrator, and 2) "make whole the victim" [2-4].

The tort system presupposes that there is an identifiable individual or group who caused a civil wrong ("tort") and further presupposes that the civil wrong was the proximate cause of the injury to the patient (victim) [5]. In lay terms, the Med-Mal system assumes that all bad medical outcomes are due to bad behavior-mistaken action or inaction-by a specific identifiable "negligent" provider [3].

\section{Results of Med-Mal}

How effective is Med-Mal in achieving its two intended outcomes: identification and "make whole"? Does Med-Mal produce unintended outcomes?

Compared to most scientific research, many published papers and reports on Med-Mal suffer from two weaknesses. First, the evidence is often non-robust data aggregated and presented without controls, comparisons or statistical analysis. Second and more important, many (one hesitates to write most) articles on Med-Mal are written for the specific purpose of advancing the author's position rather than the scientist's goal of seeking the truth. With these caveats, what does the evidence reveal?

\section{Intended consequence: Identification}

First, how effective is the Med-Mal system in identifying the guilty party and subjecting that individual to a lawsuit?

Charles et al. [5] compared the likelihood of filing a Med-Mal lawsuit with the medical events in the cases. They found no correlation with quality but a strong relationship between the initiation of a claim and the personal characteristics of the doctor. Ogbrun et al. [6] analyzed 153 Med-Mal claims made on the St. Paul Casualty Company and found that $78 \%$ of all indemnities paid were for birth trauma. They were all highly charged because the injured party was a baby.

Malpractice suits are initiated primarily on appearance rather than reality: more on how things might look than on the facts of medical causality and quality [7]. If plaintiff's lawyer believes the suit will play well to the jury, the case goes to trial. The right-or-wrong of the situation; the welfare of the victim; and compensation for the family are all determined by Games theory, seeking the solution that optimizes individual gain, rather than maximizing total benefits (net gain from the game for all).

When a patient is injured, Med-Mal generally fails to identify a specific wrongdoer for one simple reason: most of the time there is none. The vast majority of adverse outcomes are 'caused' by 
limitations in medical knowledge, not by provider ignorance or negligence. If a medication works in $85 \%$ of patients, does nothing in $10 \%$, and harms $5 \%$, the doctor does not know in which group a specific individual person will fall. In its understanding of causality and ability to predict the future for a specific patient, medicine is far behind the natural sciences. Without a clear cause-effect linkage, MedMal cannot accurately "identify" the cause or perpetrator.

\section{Intended consequence: Compensation}

Evidence shows that a payout to (compensation of) the patient bears no relationship to which patients need help or which doctors practice negligent medicine [8].

"Severity of patient's disability, not the occurrence of an adverse event or an adverse event due to negligence was predictive of payment to the plaintiff" [9].

Comparing the frequency of adverse patient impacts to the number of lawsuits filed, both Schwartz and Komesar [3] and Studdert et al. [10] showed that the majority of medically injured patients are not compensated. Studdert reviewed 1452 closed malpractice claims and reported that $84 \%$ did not result in compensation - economists would label this as "dollar Inefficient" [10].

If dollar efficiency is defined as the amount of money expended that goes to injured parties, Med-Mal is inefficient. Richards and Thomasson [11], extrapolating from their analysis of 190 closed claims in Obstetrics and Gynecology, reported that only $28 \%$ of the premiums paid for liability insurance went to patients, and that the average time to dispose of a case was 4.9 years.

The GAO (Government Accounting Office) in 1995 [4] analyzed Med-Mal cost trends in the U.S.A. including liability insurance, payouts and administrative costs. Liability premiums accounted for an average of $9 \%$ of all doctor expenses. Nationally, The U.S.A. spent between three and eight times the amounts spent on Med-Mal in European countries. Med-Mal accounted for "less than $1 \%$ of all national healthcare expenditures." When spending over $\$ 2$ trillion per year on healthcare, that amounts to $\$ 20$ billion, a staggering number but even so, less than the expense estimated by the Employment Policy Foundation [12] of $\$ 97.5$ billion.

Dollar inefficiency works two ways: failure to compensate injured patients, and paying those who should not be compensated. Evidence for the first is shown above. As for the second inefficiency (wastage), Ogbrun [6] reported that, "of those cases adjudged NOT to be negligent, 55\% paid out settlements or losses" anyway.

\section{Unintended consequence: Defensive medicine}

A direct, unintended consequence of the U.S. adversarial, tort-based Med-Mal system is defensive medicine, which both increases costs and reduces quality. Reliable, quantitative data on defensive medicine is limited for two reasons. First, what one doctor may view as unnecessary "defensive medicine" may be considered optimal practice by another. Second, the Med-Mal system itself shrouds much of such information in confidentiality protocols, unavailable to scientific analysis.

Berenson et al. [13] reported the findings of the Center for Studying Health System Changes when that organization performed site visits to 12 nationally representative medical communities. Mello [14] surveyed all training programs in Pennsylvania, a State in medical liability crisis with unsupportable liability insurance costs or (often) insurance unavailable at any price. Both reports showed that providers defend themselves by avoiding high-risk and/or non- compliant patients, and doctors often choose to avoid entering medical fields where the risk of being sued is high.

A former colleague of the author had some of the lowest mortality statistics in the U.S. when operating on morbidly obese patients. Out of 264 patients on whom he operated, two - one weighing 460 pounds and a second weighing 550 pounds-died after surgery. Their families sued the doctor and the hospital. The insurance company settled both cases. The surgeon stopped operating on this population after the second settlement.

Defensive medicine also involves ordering tests that are not medically mandatory [15] but can be used as objective, defensible data, like CAT scans for all heads injuries and echocardiograms for all children with heart murmurs.

Not only individuals but also health care institutions employ defensive behaviors. They become highly risk-averse in order to minimize their potential legal exposure [4]. Hospital Risk Management Departments implement security protocols that prevent the exchange of medical data. Hospitals will settle cases if the cost calculations warrant, even when they know the provider did nothing wrong, as in the surgical example above.

Defensive medicine wastes dollars both directly and indirectly. Two widely respected organizations-The Rand Corporation $[8,16]$ and the US GAO [4]- reported estimates of the cost of defensive medicine ranging from as little as $\$ 9$ billion to as much as $\$ 208$ billion per year. Both reports offer disclaimers that the data is "soft' and involve numerous assumptions that may not be valid. In other words, while defensive medicine wastes money, all estimates of the consequences are more guess than science.

\section{Unintended consequence: Reduced medical quality}

Possibly the most insidious and certainly the most dangerous unintended consequence of Med-Mal is the suppression of quality outcomes. Both quality improvement and error-reduction are based on learning, $[17,18]$ which in turn demands facile information sharing and risk-taking. Med-Mal actively resists both.

Most discussions about quality fail to define it properly. In 2001, British newspaper headlines exclaimed about unnecessary deaths and substandard care at a hospital supposedly famous for its excellent care of children with heart disease. A massive study was undertaken culminating in the Bristol Royal Infirmary Inquiry [19] that provided much useful information about medical quality, how frequently the word "quality" is used yet how infrequently it is defined; and how financial efficiency - considered a vital component of healthcare system quality - tends to move inversely with medical quality for patients.

In day-to-day medical practice, quality generally translates to regulatory compliance and following procedure rather than patient outcomes, especially long-term. Both medical as well as financial metrics suffer from too short time horizons and lack of measurement of positive results. Finally, many equate medical quality improvement with error reduction. They are different, as noted below in "Can you...?"

In today's litigious Med-Mal environment, no doctor would stand up and say, I made a mistake and you should learn from it, not if he or 
Page 3 of 6

she wants to keep hospital privileges, not to mention their medical license [20]. Without free and open discussion of what went wrong, there can be no improvement. Kraman and Hamm [21] studied the experience of 88 closed malpractice claims over seven years in a Lexington Veterans' Administration Hospital. Wu et al [22] did a theoretical analysis of Consequentialism (=outcomes are primary) versus Deontology (=duty comes first) applied to adverse medical impacts. Both reports came to the same conclusion: complete openness and honesty may reduce the frequency of lawsuits and thereby reduce costs.

Fear of lawsuits and of Federal regulators makes both individuals and institutions highly risk-averse. Testing a new method of care, of delivery, or even of accounting, simply does not happen in an environment where risk is a four-letter word and the medical scorecard is more important than welfare of the patient. Without risk, there can be no improvement in either medical outcomes or delivery efficiency.

\section{Unintended consequence: Liability Insurance Crisis}

Medical malpractice liability insurance is in crisis, both in terms of price as well as availability.

For providers, the cost of insurance can be prohibitive: over $\$ 200,00 /$ year for Obstetrical doctors in some States and over $\$ 30,000$ / year for nurse-midwives [23]. With average annual incomes respectively of $\$ 300,000$ and $\$ 85,000$, the cost of insurance is too high to bear and they must go "bare" (without insurance). For some providers, such as the only neurosurgeon in Wyoming, underwriters simply refused to write a policy. Pennsylvania now has only two underwriters of medical liability insurance where previously there were more than ten [24].

Because of Med-Mal, insurance companies too have major problems. Underwriting is a business: you either make more money than you spend or you go out of business. According to the Employment Policy Foundation's 2003 [12] national survey, malpractice underwriting losses totaled " $\$ 8.6$ billion in 2001, double that of ten years earlier." Underwriters try to account actuarially for how much they will pay out. This is unpredictable and (as previously shown) NOT related to the quality of medicine practiced. If they charge high enough premiums to assure sufficient income for all conceivable payouts, providers cannot afford the astronomical charges and simply go bare.

At the core of the insurance problem is the Med-Mal system, which presumes that:

Good providers never make mistakes.

Only physicians produce medical outcomes. [25]

All adverse impacts are caused by negligence and are preventable. [26]

One can always identify the appropriate negligent party to blame.

Each presumption above is incorrect.

\section{Can You...?}

Can you have a bad medical outcome without an error? : Yes, providers can do everything right, and yet patients can have bad outcomes, even die.
Can you have an error without a bad outcome? : No one likes to admit it, but errors occur tens of thousands of times each day $[26,27]$. The wrong test is done or at the wrong time or needlessly. The patient is given the wrong dosage of right drug or the wrong drug. These often occur without harm to the patient and most go unnoticed.

Can you have an effective system based on the unicorn? : This is not a humorous question. The answer is obviously No! Unicorns do not exist and neither do perfect humans [1]. Yet Med-Mal presumes that such beings-perfect, error-free providers exist and populate healthcare. The flawed reasoning continues that when bad things happen to patients, it is because the unicorns are not behaving like true unicorns: being perfect.

Can't we just reform the tort system rather than replace it? : Clearly, it would be a huge shock and highly disruptive to discard the present system. Better the devil you know than the one you don't is a phrase that resonates because it is so often true. However, when the existing system CANNOT do what we want because its design will not allow, then there is no choice.

Tort systems are predicated on the ability to link a bad outcome with the actions of an individual. Tort systems assume perfect, errorfree agents. Tort systems presume that doctors can predict and control individual medical outcomes. These assumptions simply do not apply in healthcare. No amount of adjustment of the system will make these assumptions true. Therefore, we are forced to replace rather than reform the Med-Mal tort system.

\section{Design Flaw}

Med-Mal fails to achieve its intended outcomes and produces unintended unwelcome outcomes. In plain English, we do not get what we want and what we do get is what we do not want. Using tort principles in health care is like expecting a submarine to fly.

A submarine cannot fly because it was never designed to do so. Though hydro- (not aero) dynamically efficient, a submarine has nothing in its design to create lift. The USA Med-Mal system can neither compensate injured patients nor improve quality because it was never designed to do so. No amount of modification can make a submarine airworthy and no reform of Med-Mal can produce the results expected by the public.

To compensate the injured and improve medical quality requires a new system not adaptation of the present one. As the Royal Inquiry recommended after an in-depth investigation of bad medical outcomes in the Bristol Infirmary [19], "clinical negligence litigation... should be abolished." Just like Great Britain, the U.S.A. needs tort [Med-Mal] replacement, not just tort reform.

The issue of causality is the core of design flaw in Med-Mal. Tort law is based on the establishment of a cause-effect linkage, a direct connection from doctor to injured patient, from perpetrator to victim. While some patient injuries can be tied to a bad product or a Bad Apple [1], the vast majority of adverse medical outcomes cannot. Understanding of basic mechanisms-the cornerstone of predictability and reproducibility in natural sciences such as physics and chemistrysimply does not exist in medicine (yet). A Med-Mal system that assumes knowledge of such mechanisms and that offers guaranteed results is doomed to failure.

To create a system that works, we must start with a clear description of what the system should do given the realities of medicine and its 
Page 4 of 6

practice by imperfect human beings. What are the desired and possible outputs or outcomes? What might be the unintended outcomes?

\section{Help the injured}

The most obvious desirable outcome from any "Med-Mal" system is help for the injured. Such help includes both any additional medical care required because of the injury, and financial compensation.

There are no documented cases where a patient was denied the additional care made necessary by an adverse outcome. In other words, this is a non-problem.

The additional costs are a problem. Such costs are generally passed on to the patient and the insurer. Many providers and hospitals, on advice of hospital Risk Management, will not excuse these additional costs because that could be construed as an admission of guilt.

Why, you might ask, should the patient have to pay? After all, she or he did nothing wrong. Most of the time neither did the hospital or provider. The concept that the guilty should pay, inherent in the tort system, is not applicable to health care.

A patient who has a bad outcome requires additional, unexpected care with attendant costs. Healthcare people and institutions must expend resources to provide that care. The patient and our country benefit from the patient being healthy. Those who benefit should pay. Under the present system, insurance or government pays, and then passes that cost on to premium- or tax-paying Americans.

It is widely accepted that patients with adverse outcomes should be compensated above and beyond the costs of additional care. This is the pain and suffering aspect of "make the victim whole."

Should a patient who has back pain from arthritis receive compensation for pain and suffering, suffering that was not caused by anyone? Most would say no, implying that the reason anyone would be compensated is the causation: someone did it to the patient.

Since that is only rarely true, we should discard the whole idea of extra compensation, beyond costs-of-care and lost wages.

\section{Improve the quality of medical outcomes}

There are two ways to improve medical outcomes: 1) reduce errors when using treatments that have been proven to achieve the desired outcome, and 2) doing in the future what we cannot do now, such as curing cancer of the pancreas. In 1970, childhood leukemia was uniformly fatal. Forty years later via structured learning, [28] $85 \%$ of these patients are cured (not just treated)! [29].

Both error-reduction and quality improvement require testing, risktaking and learning. Any effective Med-Mal system must encourage innovation and learning, in contrast to the current system, which is risk-averse, secretive, and rule-following.

\section{Create an Alternative to Med-Mal: The OMIn}

The U.S.A. needs more than reform of Med-Mal: it needs replacement. All the evidence above shows that the current system fails to achieve the outcomes desired by the public. It does not succeed because it cannot, not as long as it is adversarial in nature. We need to design a new system, one not based on tort principles.

A possible alternative to the current Med-Mal system is offered in Appendix I, called the Office of Medical Injuries (OMIn). It is based on No-Fault principles, similar in that regard to the No-Fault system in Sweden.

\section{Possible Drawbacks}

The OMIn has potential downsides. It will generate a large and initially expensive bureaucracy. Only as it replaces the current MedMal bureaucracy will it begin to save administrative money. There may be a legal challenge claiming Americans cannot be denied a day-incourt. Some may accuse the OMIn of insufficient compensation or failure to punish the Bad Apples. None of these concerns has stopped Sweden, Norway, Finland, and New Zealand from successfully applying a No-Fault concept to medically injured patients in preference to a tort model.

\section{Appendix I: A Proposed alternative to the current U.S. medical malpractice system - Office of Medical Injuries (OMIn)}

In Sweden and other Scandinavian countries, compensation of injured patients is not dependent on finding provider fault. One fills out a form, which is reviewed by a Board. Half of all such claims are found to be frivolous or without merit, but over $40 \%$ are awarded compensation according to a pre-set schedule for non-economic losses just like workman's compensation in the USA [30].

The OMIn would be designed to accomplish two socially desirable goals: (1) Help those injured in relation to their health care; and (2) Provide for (encourage) continuous quality improvement, which includes but is not limited to error-reduction.

The OMIn will require enabling legislation, including creation of a secure national medical database. The current Med-Mal system will not be officially dismantled but patients will be offered either the current tort system or application to the OMIn but not both.

The OMIn will have four Divisions: Compensation; Dissolution; Improvements; and Oversight. Evidence reported to or collected by OMI will not be admissible in Court.

\section{Compensation division}

A medical injury can be reported by the injured patient, by a family member, by a medical professional, or by an institution. The Compensation Section, staffed with medical experts and actuaries, will evaluate the facts of the injury, determine the severity and time of dysfunction related to the injury and offer appropriate compensation. The Compensation Division can request additional medical information even further testing in order to make its determinations. This Division will also accept testimonial and other evidence submitted by the family or patient.

The patient can, at his or her choosing, offer a different calculation for compensation based on advice from experts retained by the injured party at his/her expense. The Compensation Division will review the additional data and analysis. If it deems necessary, the Division will amend the proposed compensation scheme.

Within 90 days of completion of its analysis, the Compensation Division will pass on the case file with all the facts to both the Dissolution Division and the Oversight Division (see below). 
Page 5 of 6

\section{Dissolution division}

To "dissolve" a problem means to change the system so that the problem can never recur. [31]. The Dissolution Division is tasked with learning from the experience involved in the injury. The Division will work in concert with the involved local professionals and the Institution where the injury occurred to determine how and why the injury occurred and if possible, to design a way to prevent the injury from happening again.

The Dissolution Division will be staffed with consulting experts in both medical and management areas: from subspecialties such as Cardiology and Endocrinology to Operations, Organizational Behavior, and Technologic Innovation.

Sometimes the cause of an injury cannot be determined. In such cases, a dissolving recommendation may not be possible. In most cases, a way can be devised to prevent recurrence. The Dissolution Division will not only help develop such an improvement but monitor the implementation of the change in the Institution or system where the injury occurred.

The Dissolution Division is required to pass on its findings to the Improvement Division within 90 days of completion of study and design change. It is not required to wait until the change has been implemented and tested.

\section{Improvements division}

The Improvements Division will be staffed in a similar manner to the Dissolution Division with consultants in both medical and management areas.

The Improvements Division receives all the findings and specific recommendations from the Dissolution Division. It collates and analyzes this data looking for trends and for improvements that can be generalized: improvements that would work in many facilities rather than just the one where the original injury occurred. When such improvements are found, they are distributed to all US healthcare facilities by online distribution as well as to the Oversight Division. The Improvements Division is not tasked with overseeing the implementation of such recommended improvements. It is required only to distribute the information. Implementation is left to the discretion of each healthcare system or institution.

\section{Oversight division}

All case files as well as all recommended improvements are shared with the Oversight Division, which looks for patterns of recurring medical injuries after the wide distribution of a Dissolution Recommendation specific to that injury. Either the recommendation does not work (and the injuries recur) or institutions are being negligent. The Division, staffed primarily with experts in medicine, is tasked with determining trends and differentiating (A) recommendation failure from (B) institution or individual failure. When the Division decides it is (A), the Oversight Division confers with the Improvements Division to modify the Recommendation and then distribute the revision. When the determination is (B), the case is referred to appropriate disciplinary services, be it medical society, professional organization or an accreditation body such as JCAHO.

\section{Financing the OMIn}

As everyone benefits from the OMIn, everyone should pay for the OMIn. Like social security, there will be a large time lag between a person's payment into the OMIn and need for compensation to that individual injured patient.

It is presently impossible to predict accurately how much the OMIn will cost. A reasonable upper limit would be $\$ 20$ billion per year. This is less than any current estimate of the cost of defensive medicine alone and a small fraction of the current cost of medical liability insurance as well as legal costs, all of which will disappear as the OMIn replaces the current Med-Mal system. Net savings to the nation are likely to exceed $\$ 100$ billion per year.

A new tax will be added to what is now the social security tax, called OMIn tax. This money will be sequestered from the General Fund and accounted separately so that the actual expenses of OMI can be easily determined and the OMI tax adjusted (presumably downward) in subsequent years.

\section{References}

1. Waldman JD (2010) Uproot Healthcare. Trafford Publishing, Canada.

2. Keeton WP, Dobbs DB, Keeton RE, Owen DG (1984) Prosser and Keeton on the Law of Torts (5th Edn). West Publishing Co., USA.

3. Schwartz WB, Komesar NK (1978) Doctors, Damages and Deterrence: An economic view of medical malpractice. New Engl J Med 298: 1282-1289.

4. United States General Accounting Office (GAO) (1995) Impact on Hospital and Physician Costs Extends Beyond Insurance. Medical Liability 95.169: 1-17.

5. Charles SC, Gibbons RD, Frisch PR, Pyskoty CE, Hedeker D, et al. (1992) Predicting Risk for Medical Malpractice Claims Using Quality-of-Care Characteristics. West J Med 157:433-439.

6. Ogbrun PL, Julian TM, Brooker DC, Joseph MS, Butler JC, et al. (1988) Perinatal Medical Negligence Closed Claims from the St. Paul Company, 1980-1982. J Reprod Med 33: 608-611.

7. Waldman JD, Spector RA (2003) Malpractice claims analysis yields widely applicable principles. Pediatr Cardiol 24: 109-117.

8. Danzon PM (1986) New evidence on the frequency and severity of medical malpractice claims. Rand Corporation, Santa Monica, California.

9. Brennan TA, Sox CM, Burstin HR (1996) Relation between Negligent Adverse Events and the Outcomes of Medical-Malpractice Litigation. N Engl J Med 335:1963-1967.

10. Studdert DM, Thomas EJ, Burstin HR, Zbar BI, Orav EJ, et al (2000) Negligent Care and Malpractice Claiming Behavior in Utah and Colorado. Med Care 38: 250-260.

11. Richards BC, Thomasson G (1992) Closed Liability Claims Analysis and the Medical Record. Obstet Gynecol 80: 313-316.

12. Employment Policy Foundation (2003) Medical malpractice litigation raises health care costs, reduces access and lowers quality of care. Issuebackgrounder.

13. Berenson RA, Kuo S, May JH (2003) Medical malpractice liability crisis meets markets: stress in unexpected places. Issue Brief Cent Stud Health Syst Change 68: 1-7.

14. Mello MM, Kelly CN (2005) Effects of a professional liability crisis on residents' practice decisions. Obstet Gynecol 105: 1287-1295.

15. Kravitz RL, Rolph JE, Petersen L (1997) Omission-Related Malpractice Claims and the Limits of Defensive Medicine. Med Care Res \& Rev 54: 456-471.

16. Danzon PM (1985) Medical Malpractice: Theory, Evidence and Public Policy. Harvard University Press, Cambridge, Massachusetts, USA.

17. Berwick DM (1989) Continuous Improvement as an ideal in health care. N Engl J Med 320: 53-56. 
18. Waldman JD, Yourstone SA, Smith HL (2003) Learning Curves in Healthcare. Health Care Manage Rev 28: 43-56.

19. Bristol Royal Infirmary Inquiry. www.bristol-inquiry.org.uk/ final_report/index.htm.

20. Waldman JD (2013) The Cancer In Healthcare, Hugo House Publishers, Denver, USA.

21. Kraman SS, Hamm G (1999) Risk management: Extreme honesty may be the best policy. Ann Int Med 131: 963-967.

22. Wu AW, Cavanaugh TA, McPhee SJ, Lo B, Micco GP (1997) To tell the truth - Ethical and Practical Issues in disclosing medical mistakes to patients. J Gen Intern Med 12: 770-775.

23. Howard PK (2002) There is no 'right to sue'. Wall Street Journal.

24. Wall Street Journal Editorial (2003) "Lawyers vs. Patients---III”, p. A14.

25. Sfikas PM (1998) Are Insurers Making Treatment Decisions? J Am Dent Assoc 129: 1036-1039.

26. Leape LL (1994) Error in Medicine. JAMA 272: 1851-1857.
27. Bates DW, Spell N, Cullen DJ, Burdick E, Laird N, et al. (1997) The costs of adverse drug events in hospitalized patients. Adverse Drug Events Prevention Study Group. JAMA 277: 307-311.

28. Waldman JD, Yourstone SA (2007) Learning-The Means to Improve Medical Outcomes. Health Services Management Research 20: 227-237.

29. Horton TM, Sposto R, Brown P, Reynolds CP, Hunger SP, et al. (2010) Toxicity assessment of molecularly targeted drugs incorporated into multiagent chemotherapy regimens for pediatric acute lymphocytic leukemia (ALL): review from an international consensus conference. Pediatr Blood Cancer, Jul 1; 54(7): 872-878.

30. Rosenthal MM (1988) Dealing with medical malpractice - The British and Swedish experience. Duke University Press: Durham, North Carolina, USA.

31. Ackoff RL (1999) Ackoffs Best-His Classic Writings on Management. Wiley \& Sons, New York, USA. 